\title{
Direct clinico-histological correlation of parapapillary chorioretinal atrophy
}

\author{
Toshiaki Kubota, Jost B Jonas, Gottfried O H Naumann
}

\begin{abstract}
Parapapillary chorioretinal atrophy is a morphological feature of glaucomatous optic nerve damage since it occurs more often and is larger in glaucomatous eyes than in normal eyes. This study was undertaken to find the histological correlation. Optic disc photographs and histological sections through the optic disc of 21 human eyes enucleated because of malignant uveal melanoma were morphometrically evaluated. Seventeen eyes had normal intraocular pressure and four eyes showed elevated intraocular pressure and glaucomatous optic disc cupping. Ophthalmoscopically, the parapillary chorioretinal atrophy was divided into zone ' $\alpha$ ', located peripherally and characterised by irregular hypopigmentation and hyperpigmentation, and zone ' $\beta$ ' located close to the optic disc border and showing visible sclera and visible large choroidal vessels. Histologically, zones 'A' and ' $B$ ' were differentiated. Zone ' $A$ ' peripheral to zone ' $B$ ' showed irregularities in the retinal pigment epithelium. It consisted of an unequal distribution of melanin granules and partial atrophy of cells. In zone ' $B$ ' adjacent to the optic disc, Bruch's membrane was bared of retinal pigment epithelium cells and the photoreceptors were markedly reduced in density or were completely missing. In a direct clinical histological comparison, zone ' $A$ ' correlated significantly with zone ' $\alpha$ ' $(r=0.66 ; p<0.01)$, and zone ' $B$ ' correlated with zone ' $\beta$ ' $(r=0.99$; $p<0.0001)$. Zone 'A', 'B', ' $\alpha$ ' and ' $\beta$ ' were larger in the four glaucomatous eyes than in the normal ones. The findings indicate that zone ' $\beta$ ' represents histologically a complete loss of retinal pigment epithelium cells and an incomplete loss of adjacent photoreceptors. Zone ' $\alpha$ ' may be the histological correlate of irregularities in the retinal pigment epithelium. (Br f Ophthalmol 1993; 77: 103-106)
\end{abstract}

In the parapapillary region of eyes with glaucomatous optic nerve atrophy, chorioretinal abnormalities have been reported to be larger and to occur more often than in the parapapillary region of normal eyes. ${ }^{1-17}$ They have been described as 'halo glaucomatosus' in eyes with end stage glaucoma. ${ }^{18-20}$. We have previously described them as zone ' $\beta$ ' and zone ' $\alpha$ '..$^{1314}$ Zone ' $\beta$ ' adjacent to the optic disc showed visible 'bared' sclera and visible large choroidal vessels. Zone ' $\alpha$ ' peripheral to zone ' $\beta$ ' was characterised by an irregular hypopigmentation and hyperpigmentation. Zone ' $\alpha$ ' bordered directly on the optic disc if zone ' $\beta$ ' was not present. The latter was interposed between zone ' $\alpha$ ' and the disc border. In clinical cross section studies, both zones correlated in extent and space with the intrapapillary neuroretinal rim loss, retinal nerve fibre layer defects, reduction of the retinal vessel diameter in the parapapillary region, and perimetric defects in corresponding visual field quadrants..$^{1314} 1721$

In a recent histomorphometric investigation, it was hypothesised that the ophthalmoscopic appearance of zone ' $\beta$ ' was based on a complete loss of retinal pigment epithelium cells and on an incomplete loss of photoreceptors. ${ }^{22}$ Zone ' $\alpha$ ' was thought to represent pigment irregularities at the level of the retinal pigment epithelium. In search of the histological correlate of zones ' $\alpha$ ' and ' $\beta$ ', the present study was undertaken to perform a direct clinical histological correlation of the parapapillary chorioretinal atrophy in eyes with optic disc photographs taken before enucleation.

\section{Materials and methods}

Twenty one eyes of 21 patients (five men, 16 women, mean age 57 (SD 15.2; range 10-81) years had been enucleated owing to a malignant uveal melanoma. Before enucleation, optic disc photographs had been taken. In 17 of the eyes, the intraocular pressure (IOP) had been normal. In four eyes the IOP was elevated to readings ranging between $21 \mathrm{~mm} \mathrm{Hg}$ and $40 \mathrm{~mm} \mathrm{Hg}$. These four eyes showed glaucomatous optic disc cupping and glaucomatous perimetric changes as well as visual field defects caused by the tumour itself. Five days before removal of the globe the eyes had received radiation with a daily rate of 4 Gy.

All globes were fixed immediately after enucleation in a solution of $4 \%$ formaldehyde $/ 1 \%$ glutaraldehyde. Periodic acid Schiff stained histological sections were prepared through the optic disc and pupil. The histological slide going closest through the optic disc centre was selected for evaluation. Using a planimeter tablet with the cursor illuminated and mirrored into the microscope, we determined: (1) the distance between the two ends of Bruch's membrane, (2) the thickness of the peripapillary scleral ring directly 
beneath Bruch's membrane, (3) zone 'B', defined as the length of Bruch's membrane bared of retinal pigment epithelium cells and located peripheral to the peripapillary scleral ring, and (4) zone ' $A$ ', adjacent to zone ' $B$ ' and defined as the length of Bruch's membrane covered by retinal pigment epithelium cells irregularly pigmented and structured (Fig 1).

The optic disc photographs were projected to magnification of 1 to 15 . The outlines of the

Figure 1 Optic disc photograph $(A)$ and histological slides (PAS stained) through the parapapillary area (temporal side $(B)$; nasal side $(C)$ ) of an eye obtained from a 10 year old boy with a uveal malignant melanoma and secondary open angle glaucoma. The white line on $(A)$ indicates the direction of the histological section as shown in $(B)$ and $(C)$. (A) Long arrows: zone ' $\alpha$ ', short arrow: peripapillary scleral ring; arrowheads: conus pigmentosus. (B) Arrows: zone ' $A$ ' between arrow and asterisk: peripapillary scleral ring. (C) Arrows:

hypertrophy of the retinal pigment epithelium. Bar $=50 \mu \mathrm{m}$.
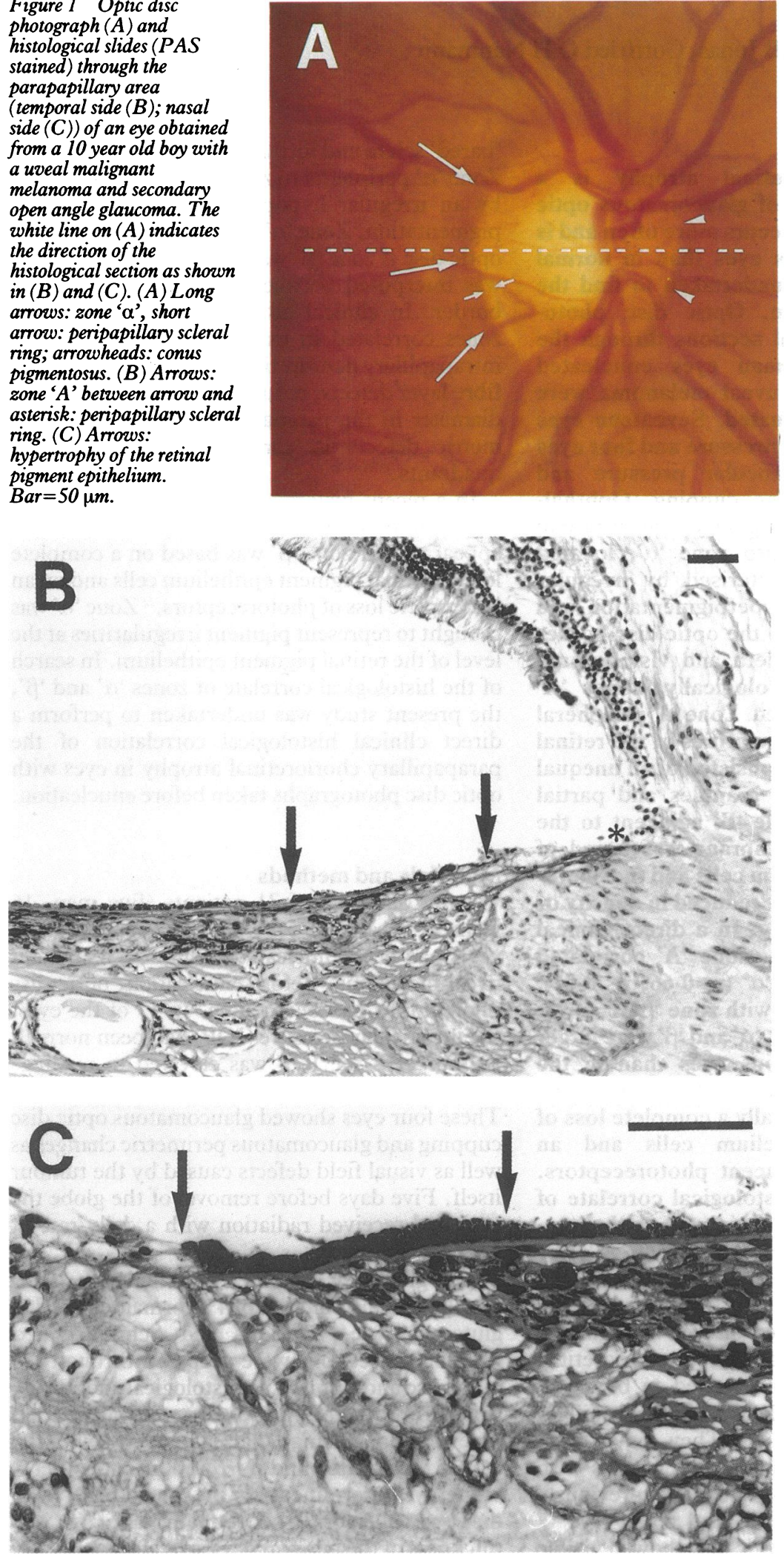

optic disc, peripapillary scleral ring, and parapapillary chorioretinal atrophy were plotted on paper. The optic disc was defined as all the area within the peripapillary scleral ring. The latter was a white band encircling the optic disc. The parapapillary chorioretinal atrophy was divided into zones ' $\alpha$ ' and ' $\beta$ '. ${ }^{131+17}$ The ocular and camera magnification were corrected according to Littman. ${ }^{23}$ In the same meridian in which the globe had been sectioned histologically we measured the diameters of the optic disc, peripapillary scleral ring, and zones ' $\alpha$ ' and ' $\beta$ '. The histological evaluation and the morphometric analysis of the disc photographs were performed independently by two different investigators.

\section{Results}

Comparing the histomorphometric and biomorphometric data, histological zone ' $A$ ' correlated significantly with zone ' $\alpha$ ' (correlation coefficient: $r=0.66$; slope of the regression line: $+0.65 ; p<0.01$ ). Histological zone ' $B$ ' correlated significantly with zone ' $\beta$ ' $(r=0.99$; slope of the regression line; $+1.08 ; p<0.0001)$. In the nonglaucoma group the size of histological zone ' $B$ ' was significantly correlated with the axial length of the globe $(r=0.71 ; p<0.005)$. If eyes with an axial length exceeding $26 \mathrm{~mm}$ were excluded, zones ' $A$ ' and ' $B$ ' and ' $\alpha$ ' and ' $\beta$ ' were on an average larger in the four glaucoma eyes compared with the 15 remaining normal eyes (zone 'A' 0.228 (SD 0.124) mm versus 0.096 (SD 0.072) $\mathrm{mm}$, zone 'B': 0.015 (SD 0.023) mm versus 0.013 (SD 0.034) $\mathrm{mm}$; zone ' $\alpha$ ': $0 \cdot 163$ (SD $0.065) \mathrm{mm}$ versus $0.097(\mathrm{SD} 0.102) \mathrm{mm}$; zone ' $\beta$ ': 0.048 (SD 0.095) $\mathrm{mm}$ versus $0 \mathrm{~mm}$ ). The difference was not significant on a $5 \%$ level of error of probability.

In one eye, a 'conus pigmentosus' was present correlating histologically with a hypertrophy of the retinal pigment epithelium close to the optic disc border (Fig 1A, 1C).

\section{Discussion}

In this study of a direct biomorphometric histomorphometric comparison, a statistically significant correlation was found between the parapapillary chorioretinal atrophy, determined ophthalmoscopically on the one hand and histologically on the other. Zone ' $\alpha$ ' may represent pigmentary and structural irregularities of the retinal pigment epithelium, and zone ' $\beta$ ' may correlate with a complete loss of retinal pigment epithelium cells and an incomplete loss of photoreceptors (Fig 1).

For several decades, atrophic changes in the parapapillary region have been described as occurring in some eyes with advanced glaucomatous optic nerve atrophy. ${ }^{1-718-20}$ Recently, parapapillary atrophic alterations were reported in eyes with moderate glaucomatous optic nerve damage. ${ }^{12-1+}$ In a retrospective study, Anderson and colleagues examined 127 glaucoma patients and 49 control individuals. Over time they observed parapapillary abnormalities in the form of retinal pigment epithelium changes in $21 \%$ of the glaucoma patients with progressive glaucomatous cupping and in $4 \%$ of normal control 
subjects. The acquired changes were estimated to be too small and too infrequent to account for the high prevalence of large haloes in the parapapillary region in glaucoma eyes. ${ }^{12}$ In an investigation of 137 healthy subjects and 195 subjects with ocular hypertension, a lower prevalence rate of crescent was found in the ocular hypertensive group than among the healthy subjects. ${ }^{15}$ In another study the average area of bared choroid and sclera was greater in eyes with normal tension glaucoma than in those with ocular hypertension. The authors assumed that the absence of a crescent decreased the risk of glaucomatous damage from elevated IOP. ${ }^{16}$ It fits the hypothesis that the parapapillary chorioretinal atrophy may be important pathogenetically for the glaucomatous optic nerve fibre loss. As recently discussed in the literature, ${ }^{24}$ an altered area of contact between the choroid and the optic disc, without an interposed cellular layer barrier, might affect the degree of influence of substances that may diffuse from the choroid into the optic nerve head. Additionally, it was concluded that the presence of a crescent correlated with the glaucomatous disc damage.

These findings were contradicted by studies in which the parapapillary atrophy was not found to be significantly different between eyes with unilateral secondary glaucoma and the contralateral normal eye, ${ }^{24}$ or in eyes with high and low tension glaucoma. ${ }^{25}$ Also, in another study, the parapapillary chorioretinal atrophy was not a sufficiently sensitive or specific parameter to predict the development of visual field defects in a follow up examination of ocular hypertensive subjects. ${ }^{26}$

In a recent histological study, Fantes and Anderson described an irregular pigmentation occurring when the retinal pigment epithelium adjacent to the disc lacked pigment or was hyperpigmented. ${ }^{27}$ Our study confirmed these findings elucidating the differentiation between the ophthalmoscopical zones ' $\alpha$ ' and ' $\beta$ ' and the histological zones ' $A$ ' and ' $B$ '. It agrees with another histological study that compared the parapapillary chorioretinal atrophy in human eyes enucleated because of painful secondary angle closure glaucoma or malignant choroidal melanoma without glaucoma. ${ }^{22}$ It also agrees with a comparison of the blind spot size and the area of the parapapillary chorioretinal atrophy. ${ }^{28}{ }^{29}$ In these studies zone ' $\alpha$ ' was attributed to a relative scotoma, and zone ' $\beta$ ' to an absolute scotoma. Histologically, the relative scotoma of zone ' $\alpha$ ' can be explained by the irregularities of the retinal pigment epithelium cells, and the absolute scotoma of zone ' $\beta$ ' can histologically be based on the loss of photoreceptors and retinal pigment epithelium cells.

Biomorphometrically, zones ' $\alpha$ ' and ' $\beta$ ' are significantly larger in glaucomatous eyes compared with normal ones. ${ }^{131417}$ In the present study, zones ' $\alpha$ ' and ' $\beta$ ' as well as zones ' $A$ ' and ' $B$ ' were larger in the glaucoma group than in the control group. The differences, however, were not significant, probably because of the small number of cases in the subgroups.

Pathogenetically, it remains unclear whether the parapapillary chorioretinal atrophy predisposes to glaucoma or whether it occurs parallel to or in consequence of the glaucomatous optic nerve fibre loss. The fact that in histological zone ' $B$ ' the retinal pigment epithelium was completely lost and the retinal photoreceptors were still partially present suggests that the parapapillary choriocapillaris may be responsible for the atrophy. It has been hypothesised that the increased IOP reduces the choroidal blood flow in the parapapillary region and has been shown in several studies. ${ }^{30} 31$ This could lead firstly to damage of the retinal pigment epithelium cells and later to a loss of photoreceptors.

Clinically, the parapapillary chorioretinal atrophy has been described as being more common in glaucomatous eyes with moderately elevated IOP, shallow disc cupping, and marked tessellated fundus compared with glaucomatous eyes with high IOP readings, deep optic disc cupping, and less marked tessellated fundus. ${ }^{17}$ With respect to glaucomatous changes in the deep retinal layers, it remains unclear if glaucomatous eyes with a large parapapillary chorioretinal atrophy exhibit a loss of retinal pigment epithelium cells and photoreceptors only in the area close to the optic disc or whether they show a disseminated loss and alteration of retinal pigment epithelium cells and photoreceptors and uveal changes across the whole fundus as reports have previously suggested for eyes with secondary angle closure glaucoma. ${ }^{32} 33$

In one eye of the present study, a conus pigmentosus or pigment ring was present at the optic disc border (Fig 1). Ophthalmoscopically, it has to be differentiated from zone ' $\alpha$ ' and histologically, it correlated with a hypertrophy of the retinal pigment epithelium. This indicates that it consists of pigment epithelium cells with an abnormal high grade of pigmentation with an otherwise normal structure and this is in contrast to zone ' $\alpha$ ' which is characterised by a clumping and an irregular arrangement of retinal pigment epithelium cells.

This work was supported by grants from the Alexander von Humboldt-Foundation (grant no 13648, T Kubota) and Deutsche Forschungsgemeinschaft (Klinische Forschergruppe 'Glaukome', DFG Na 55/6-1/Jo)

The authors wish to thank Mrs C Rummelt and Ms S Herman for their technical assistance.

1 Primose J. Early signs of the glaucomatous disc. $B r f$ Ophthalmol 1971; 55: 820-5.

2 Primose J. The incidence of the peripapillary halo glaucomatosus. Trans Ophthalmol Soc UK 1971; 89: 585-7.

3 Hayreh SS. Blood supply of the optic nerve head and its role in the optic atrophy, glaucoma and oedema of the optic disc. $\mathrm{Br}$ fOphthalmol 1969; 53: 721-48.

4 Raitta C, Sarmela T. Fluorescein angiography of the optic disc and peripapillary area in chronic glaucoma. Acta Ophthalmol 1970; 48: 303-8.

5 Hayreh SS. Optic disc changes in glaucoma. Br $\mathcal{F}$ Ophthalmol 1972; 56: 175-85.

6 Wilensky JT, Kolker AE. Peripapillary changes in glaucoma. Am $\mathcal{F}$ Ophthalmol 1976; 81: 341-5.

7 Primrose J. Peripapillary changes in glaucoma. Am 7 Ophthalmol 1977; 83: 930-1.

8 Anderson DR. Correlation of the peripapillary damage with the disc anatomy and field abnormalities in glaucoma. Doc Ophthalmol Proc Ser 1983; 35: 1-10.

9 Heijl A, Samander C. Peripapillary atrophy and glaucomatous visual field defects. Doc Ophthalmol Proc Ser 1985; 42: 4037.

Airaksinen PJ, Juvala PA, Tuulonen A, Alanko HI, Valkonen $R$, Tuohino A. Change of peripapillary atrophy in glaucoma. In: Kreiglstein GK, ed. Glaucoma update III. Berlin Heidelberg: Springer-Verlag, 1987: 97-102.

11 Anderson DR. Relationship of peripapillary haloes and crescents to glaucomatous cupping. In: Krieglstein GK, ed. Glaucoma update III. Berlin, Heidelberg: Springer-Verlag, 1987: 103-5. 
12 Rockwood EJ, Anderson DR. Acquired peripapillary changes and progression in glaucoma. Graefes Arch Clin Exp Ophthalmol 1988; 226: $510-5$.

13 Jonas JB, Nguyen XN, Gusek GC, Naumann GOH. Parapapillary chorio-retinal atrophy in normal and glaucoma eyes. I. Morphometric data. Invest Ophthalmol Vis Sci 1989 30: $908-18$

14 Jonas JB, Naumann GOH. Parapapillary chorioretina atrophy in normal and glaucoma eyes. II. Correlations. Invest Ophthalmol Vis Sci 1989; 30: 919-26.

15 Kasner O, Feuer WJ, Anderson DR. Possibly reduced prevalence of peripapillary crescents in ocular hypertension. Can $\mathcal{}$ Ophthalmol 1989; 24: 211-5.

16 Buus DR, Anderson DR. Peripapillary crescents and halos in normal-tension glaucoma and ocular hypertension. Ophthalmormal-tension glaucoma

17 Jonas JB, Fernández MC, Naumann GOH. Glaucomatous parapapillary chorioretinal atrophy: occurrence and correlations. Arch Ophthalmol 1992; 110: 214-22.

18 Elschnig A. Über Glaukom. Graefes Arch Ophthalmol 1928; 120: 94-116.

19 Elschnig A. Glaukom. In: Henke-Lubarsch, ed. HenkeLubarschs Handbuch der speziellen pathologischen Anatomie und Histologie, Vol XI. Berlin: Springer-Verlag, 1928: 873.

20 Thiel R, Glaukom. In: Schieck F, Brïckner A eds. Kurez Handbuch der Ophthalmologie, Band IV. Berlin: Springer Verlag, 1931; 758: 725-6.

21 Jonas JB, Nguyen NX, Naumann GOH. Die retinale Nervenfaserschicht in Normal- und Glauke retinale Korvenfationen. Klin Monatsbl Augenheilkd 1989; 195: 30814.

22 Jonas JB, Königsreuther KA, Naumann GOH. Optic disc histomorphometry in normal eyes and eyes with secondary angle-closure glaucoma. II. Parapapillary region. Graefes Arch Clin Exp Ophthalmol 1992; 230: 134-39.

23 Littmann H. Zur Bestimmung der wahren Größe eines Objektes auf dem Hintergrund des lebenden Auges. Klin Monatsbl Augenheilkd 1982; 180: 286-9.
24 Fantes FE, Anderson DR. Clinical histologic correlation of human peripapillary anatomy. Ophthalmology 1989;96: 20 5.

25 Nevarez J, Rockwood EJ, Anderson DR. The configuration of peripapillary tissue in unilateral glaucoma. Arch Ophthalmol 1988; 106: 901-3.

26 Caprioli J, Spaeth GL Comparison of the optic nerve head in high- and low-tension glaucoma. Arch Ophthalmol 1985; 103: 1145-9.

27 Airaksinen PJ, Tuulonen A, Alanko H. Prediction of develop ment of glaucoma in ocular hypertensive patients. In Krieglstein GK, ed. Glaucoma update IV. Berlin, Heidelberg, New York: Springer-Verlag, 1991; 186: 183-6.

28 Jonas JB, Gusek GC, Fernandez MC. Correlation of the blind spot size to the area of the optic disk and parapapillary atrophy. Am f Ophthalmol 1991; 111: 559-65.

29 Stürmer J, Schroedel C, Rappl W. Low-backgroundbrightness, static SLO fundus-perimetry. Invest Ophthalmo Vis Sci (Suppl) 1990; 31: 504.

$30 \mathrm{Alm}$ A, Bill A. The oxygen supply to the retina. II: Effects of high intraocular pressure and of increased carbon dioxide tension on uveal and retinal blood flow in cats: a study with labelled microspheres including flow determinations in brain and some other tissues. Acta Physiol Scand 1972; 84: 306-19.

$31 \mathrm{~A} \operatorname{m}$ A, Bill A. Ocular and optic nerve blood flow at normal and increased intraocular pressures in monkeys (Macaca irus): study with radioactively labelled microspheres including flow determinations in brain and some other tissues. Exp Eye Res 1973; 15: 15-29.

32 Ueno $M$, Naumann GOH. Uveal damage in secondary glaucoma. A comparative study. Graefes Arch Clin Exp Ophthalmol 1989; 227: 380-3.

33 Panda S, Jonas JB. Decreased photoreceptor count in human eyes with secondary angle-closure glaucoma. Invest Ophthat mol Vis Sci 1992; 33: 2532-6. 